\title{
Pengaruh Konsentrasi Larutan Kitosan dan Volume Cross-linker Terhadap Kinetika Release Mikrokapsul Oleoresin Jahe Merah Dalam Medium Simulated Intestinal Fluid (SIF)
}

\section{Chitosan Concentration and Cross-linker Volume Effect on The Release Kinetic of Red Ginger Oleoresin Microcapsule in Simulated Intestinal Fluid (SIF) Medium}

\author{
Jayanudin $^{\mathrm{a}, \mathrm{b}^{*}}$, Moh. Fahrurrozi ${ }^{\mathrm{a}}$, Sang Kompiang Wirawan ${ }^{\mathrm{a}}$ dan Rochmadi $^{*}$ \\ ${ }^{a}$ Departemen Teknik Kimia, Fakultas Teknik, Universitas Gadjah Mada. \\ Jl. Grafika No. 2 Yogyakarta, 55281, Indonesia \\ ${ }^{b}$ Jurusan Teknik Kimia, Fakultas Teknik, University of Sultan Ageng Tirtayasa. \\ Jl. Jenderal Sudirman km.3, Cilegon, 42435, Indonesia
}

\section{Artikel histori : \\ Diterima 25 April 2019 Diterima dalam revisi 4 Agustus 2019 Diterima 24 Oktober 2019 Online 31 Oktober 2019}

\begin{abstract}
ABSTRAK: Oleoresin jahe merah mengandung komponen yang dapat digunakan sebagai antioksidan. Studi kinetika release digunakan untuk menyediakan dosis untuk pencapaian konsentrasi obat yang sesuai. Tujuan penelitian ini adalah menentukan kinetika release mikrokapsul oleoresin jahe berdasarkan perubahan konsentrasi kitosan dan volume agen crosslink dan menentukan koefisien difusi oleoresin jahe merah melalui dinding mikrokapsul. mikrokapsul oleoresin jahe merah dipreparasi dari campuran oleoresin jahe merah dalam larutan kitosan dan diaduk untuk membentuk emulsi. seteleh itu ditambahkan ke minyak jagung dan diaduk kembali untuk membentuk emulsi kedua. Glutaraldehyde saturated toluene diteteskan sedikit demi sedikit setelah selesai ditambahkan 25\% larutan glutaraldehida dan tetap diaduk selama 2 jam. mikrokapsul oleoresin jahe merah dipisahkan dan dicuci dengan petroleoum eter dan heksan, kemudian dikeringkan dalam oven. Mikrokapsul di masukkan dalam medium release yaitu simulated intestinal fluid tanpa enzim kemudian sampel dianalisis menggunakan spektrofotometer UV-vis untuk mengetahui absorbansinya. Nilai koefisien relasi $\left(R^{2}\right)$ tertinggi didapat dari model kinetika release Korsmeyer-Peppas yaitu $R^{2}=0.73-0.85$ dengan nilai $\mathrm{n}=0.39-0.41$. Berdasarkan nilai $\mathrm{n}$ tersebut mekanisme release dari mikrokapsul oleoresin jahe merah adalah secara Fickian. Koefisien difusi yang dihasilkan yaitu 2.807 x 10$13-3.675 \times 10^{-13} \mathrm{~cm}^{2} /$ detik.
\end{abstract}

Kata Kunci: kinetika release;kitosan;oleoresin jahe merah;stimulated intestinal fluid

\begin{abstract}
Red ginger oleoresin contains components that can be used as antioxidants. Release kinetics studies are used to provide doses to achieve the desired drug concentration. The purpose of this study was to determine the release kinetics of red ginger oleoresin microcapsules based on changes in chitosan concentration and volume of cross-linker and determine the diffusion coefficient of red ginger oleoresin through microcapsule walls. Red ginger oleoresin microcapsules were prepared from a mixture of red ginger oleoresin in chitosan solution and stirred to form an emulsion. After that, it was added to corn oil and stirred again to form a second emulsion. Glutaraldehyde saturated toluene was added dropwise after finished added the $25 \%$ glutaraldehyde solution and remains stirred for 2 hours. Red ginger oleoresin microcapsules were separated and washed with petroleum ether and hexane, then dried in an oven. Microcapsules inserted in the release medium (simulated intestinal fluid) without enzymes, and then the samples were analyzed using a UV-vis spectrophotometer to determine the absorbance. The release kinetics models used were zero order, first order, Higuchi, Korsmeyer-Peppas, and Hixon-Crowell. The highest correlation coefficient (R2) was obtained from the Korsmeyer-Peppas release kinetics model, $\mathrm{R}^{2}=0.73-0.85$ with the value of $\mathrm{n}=0.39-0.41$. Based on the $\mathrm{n}$ value, the release mechanism of red ginger oleoresin microcapsules was Fickian diffusion. The diffusion coefficients obtained were 2,807 x $10^{-13}$ $3,675 \times 10^{-13} \mathrm{~cm}^{2} / \mathrm{sec}$.
\end{abstract}

Keywords: Chitosan;release kinetics;red ginger oleoresin;stimulated intestinal fluid 


\section{Pendahuluan (Introduction)}

Enkapsulasi merupakan suatu proses perlindungan bahan aktif dari pengaruh lingkungan supaya tidak terjadi degradasi sehingga dapat menghilangkan fungsi utama dari bioaktif tersebut. Selain itu, enkapsulasi bertujuan untuk mengontrol pelepasan bioaktif untuk mempertahankan konsentrasi obat dalam darah sehingga dapat mencapai jaringan target yang diinginkan dengan waktu tertentu. Pelepasan terkendali (controlled release) digunakan untuk melepaskan sebagian dosis untuk mencapai konsentrasi obat yang efektif. Pengaruh lain adalah mengurangi asupan obat dan mengurangi efek samping yang berhubungan dengan pemberian dosis obat. Kinetika release obat digunakan untuk mengetahui penyediaan dosis untuk mencapai konsentrasi obat yang diinginkan (Dash dkk, 2010).

Model-model kinetika release yang banyak digunakan adalah model order nol, order satu, model Higuci, model Korsmeyer-Peppas, model HixsonCrowell, model Baker-Lonsdale, dll. Model-model tersebut didasarkan pada fungsi matematis yang berbeda untuk menggambarkan profil disolusi. Setelah fungsi dipilih, profil disolusi dievaluasi tergantung pada parameter model yang diturunkan. Untuk menentukan model kinetika release yang sesuai menggambarkan profil disolusi (Freitas dan Marchetti, 2005; Dash dkk, 2010). Model kinetika release mempunyai aplikasi tersendiri, misalkan model kinetika order nol diaplikasikan untuk menggambarkan disolusi obat dari beberapa jenis sediaan farmasi release yang dimodifikasi seperti untuk kasus sistem transdermal, tablet matriks dengan obat yang larus dalam bentuk berlapis, sistem osmotik, dll. Sedangkan untuk model Higuchi diaplikasi untuk menggambarkan disolusi pada sisitem transdermal dan tablet matriks yang mengandung obat yang larut dalam air (Shoaib dkk, 2006; Dash dkk, 2010)

Pada penelitian ini bertujuan untuk menentukan kinetika release oleoresin jahe merah dari mikrokapsul. oleoresin jahe merah merupakan produk ekstraksi jahe merah yang mengandung bahan-bahan aktif utama seperti gingerol, shogaol, dan zingiberene. Bioaktif tersebut dapat digunakan sebagai antioksidan, antibakteri, dan anti-inflamasi (Ravindran dkk, 2005; Bellik, 2014; Oboh dkk, 2012). Kelemahan dari oleoresin jahe merah sama dengan kekurangan oleoresin pada umumnya yaitu sensitive terhadap oksigen, panas, dan cahaya (Shaikh dkk, 2006; Vaidya dkk, 2006). Faktor-faktor tersebut dapat mendegradasi bioaktif yang terkandung dalam oleoresin jahe merah sehingga dapat menurunkan kualitasnya bahkan tidak bermanfaat sama sekali. Metode yang dapat digunakan untuk melindungi oleoresin jahe merah dari degradasi karena pengaruh lingkungan dan sekaligus juga dapat digunakan untuk pelepasan terkendali yaitu dengan metode enkapsulasi.

Metode enkapsulasi yang digunakan pada penelitian ini adalah crosslink emulsi karena metode ini cukup sederhana dan mudah. Metode crosslink emulsi berkaitan dengan interaksi antara gugus fungsi polimer (biopolimer) sebagai bahan dinding mikrokapsul dengan gugus fungsi cross-linker. Pengaruh dari crosslink tersebut dapat terbentuk partikel-partikel pada yang berbagai ukuran. Metode crosslink emulsi merupakan metode enkapsulasi yang serba guna karena dapat digunakan untuk melindungi bahan yang saling larut, bahan yang tidak saling larut, cairan dan padatan, dan juga dapat menghasilkan partikel dengan ukuran mikro sampai nanopartikel (Manjanna dkk, 2010). Penyalut yang digunakan adalah kitosan karena bersifat biokompatibel, biodegradabel dan tidak beracun (Islam dkk, 2017). Cross-linker yang digunakan untuk ditaut silang dengan kitosan adalah glutaraldehyde saturated toluene (GST) karena mudah larut dalam medium minyak dan menghasilkan reaksi silang yang seragam sehingga dapat menghasilkan mikrokapsul yang berbentuk bola sempurna dengan permukaan yang halus (Thanoo dkk, 1992).

Jumlah oleoresin jahe merah release dari mikrokapsul, ukuran partikel, dan ketebalan dinding mikrokapsul sudah dilaporkan oleh Jayanudin dkk. (2018), tetapi dalam artikel tersebut belum dilaporkan mengenai kinetika release yang terjadi. Pada penelitian ini juga menentuan koefisien difusi menggunakan persamaan yang berbeda dengan yang dilaporkan oleh Jayanudin dkk. (2019) sehingga dapat dibandingkan dari nilai koefisien difusi yang dihasilkan.

\section{Metode Penelitian}

\subsection{Bahan}

Bahan penelitian yang digunakan adalah oleoresin jahe merah yang diperoleh dari CV. Lansida group, larutan glutaraldehida dengan konsentrasi 25\% yang berasal dari Merck, larutan petroleum eter dan heksana merupakan grade teknis diperoleh dari CV. Labora, larutan toluene teknis dengan konsentrasi 96\% diperoleh dari CV. Tri Jaya Dinamika, kitosan diproduksi oleh PT. Biotech Surindo, minyak jagung diproduksi CV. Surya Agung, $\mathrm{NaOH}$, dan KH2PO4 didapat dari Merck

\subsection{Enkapsulasi oleoresin jahe merah menggunakan metode crosslink emulsi}


Metode crosslink emulsi mengacu pada penelitian yang dilaporkan oleh Jameela and Jayakrishnan, (1995), Campos dkk. (2013), Ofokansi dkk. (2013), dan Jayanudin dkk, 2018. Empat gram oleoresin jahe merah dimasukan dalam $40 \mathrm{~mL}$ larutan kitosan dengan konsentrasi $1 \%, 2 \%, 3 \%$, dan $4 \%$ (w/v), campuran tersebut diaduk menggunakan homogenizer dengan kecepatan $10.000 \mathrm{rpm}$ selama 30 menit untuk membentuk emulsi. Setelah itu, emulsi tersebut dimasukan dalam $150 \mathrm{~mL}$ minyak jagung dan diaduk kembali selama 1 jam sehingga membentuk emulsi oil in water in oil $(\mathrm{O} / \mathrm{W} / \mathrm{O})$. Sebanyak $10 \mathrm{~mL}$ crosslinker (glutaraldehyde saturated toluen) diteteskan secara pelahan sampai habis, setelah itu ditambahkan $2 \mathrm{~mL}$ larutan gluatarldehida dengan konsentrasi $25 \%$ (v/v) dan tetap diaduk selama 2 jam. Mikrokapsul yang terbentuk dipisahkan dengan sentrifuge dan dicuci menggunakan petroleum eter dan heksana. Tahap akhir adalah mikrokapsul dikeringkan dengan oven pada suhu $75^{\circ} \mathrm{C}$.

\subsection{Analisis release oleoresin jahe merah dari mikrokapsul}

Analisis release oleoresin jahe merah dari mikokopsul (Jayanudin dkk.,2019). Medium lambung buatan atau yang disebut dengan simulated intestinal fluid (SIF) untuk menentukan jumlah oleoresin jahe merah yang release. Medium SIF ini merupakan larutan buffer fosfat pada $\mathrm{pH} \mathrm{7,4} \mathrm{yang} \mathrm{dibuat} \mathrm{dengan} \mathrm{mencampurkan}$ larutan $0.2 \mathrm{M} \mathrm{NaOH}$ ke dalam larutan 0.2 M KH2PO4 sampai $\mathrm{pH}$ campuran menjadi 7,4. Oleoresin jahe merah dimasukan dalam beker gelas yang berisi medium SIF kemudian diaduk dengan kecepatan 220 rpm dan pada suhu $37 \square$ C. sebanyak $10 \mathrm{~mL}$ sampel diambil dengan rentang waktu tertentu dan dianalisis menggunakan spektrofotometer UV-Vis pada panjang gelombang $283 \mathrm{~nm}$. Nilai absorbansi yang terukur digunakan untuk menentukan konsentrasi oleoresin jahe merah dalam medium SIF.

\subsection{Model kinetika release}

Terdapat lima model kinetika release yang telah dikembangkan Jayanudin dkk. (2018), DozieNwachukwu dkk. (2017). Model-model kenetika release yang digunakan adalah sebagai berikut :

1. Zero order

$$
\frac{\mathrm{M}_{\mathrm{t}}}{\mathrm{M}_{m}}=\mathrm{k}_{0} \mathrm{t}
$$

2. First order

$$
\frac{\mathrm{M}_{\mathrm{E}}}{\mathrm{M}_{\infty}}=1-\exp \left(-\mathrm{k}_{1} \mathrm{t}\right)
$$

3. Higuchi model

$$
\frac{\mathrm{M}_{\mathrm{L}}}{\mathrm{M}_{\mathrm{m}}}=\mathrm{k}_{\mathrm{H}^{\mathrm{t}}} \mathrm{t}^{1 / 2}
$$

4. Korsmeyer-Peppas model

$$
\frac{\mathrm{M}_{\mathrm{t}}}{\mathrm{M}_{\mathrm{me}}}=\mathrm{k}_{\mathrm{K}-\mathrm{p}} \mathrm{t}^{\mathrm{n}}
$$

5. Hixon-Crowell model

$$
\mathrm{W}_{\mathrm{0}}^{1 / 2}-\mathrm{W}_{\mathrm{t}}^{1 / 2}=\mathrm{k}_{\mathrm{H}-\mathrm{C}^{\mathrm{t}}}
$$

Untuk menentukan koefisien difusi (D) menggunakan persamaan yang telah dilaorkan oleh Siepman (2012) yang dapat diekspresikan pada persamaan 6 .

$$
\frac{M_{t}}{M_{-}}=1-\exp \left[\frac{3 R_{0} D K t}{R_{i}^{2} R_{0}-R_{i}^{3}}\right]
$$

\section{Hasil dan Pembahasan}

3.1. Pengaruh konsentrasi kitosan dan volume crosslinker terhadap oleoresin jahe merah yang release dari mikrokapsul

Jumlah oleoresin jahe merah yang release dari mikrokapsul berdasarkan perubahan konsentrasi kitosan sebagai bahan dinding mikrokapsul dan volume glutaraldehyde saturated toluene (GST) sebagai crosslinker dapat dlihat pada Gambar 1 dan 2. Perubahan kumulatif release oleoresin jahe merah dari mikrokapsul sebelumnya sudah dilaporkan oleh Jayanudin dkk (2019). Gambar 1 menunjukkan bahwa kumulatif release terkecil diperoleh dari mikrokapsul yang dipreparasi dari konsentrasi kitosan $1 \%$ yaitu sebesar 58,71\% sedangkan untuk kumulatif release terrendah yaitu sebesar 51,69\% yang diperoleh dari mikrokapsul yang dipreparasi dari kitosan dengan konsentrasi 4\% (w/v).

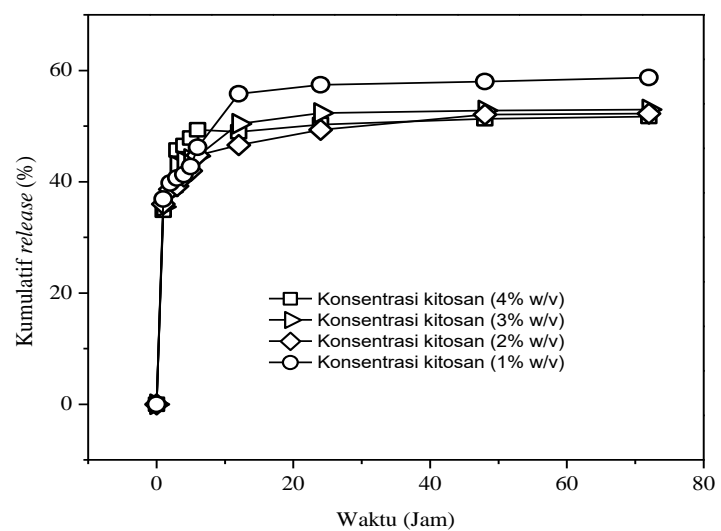

Gambar 1. Persen kumulatif release oleoresin jahe merah untuk berbagai konsentrasi kitosan dengan 10 $\mathrm{mL}$ glutaraldehyde saturated toluene (GST)

Gambar 1 menunjukkan bahwa untuk konsentrasi kitosan 2\%,3\%, dan 4\% (w/v) menghasilkan kumulatif release yang hampir sama nilanya yaitu terjadi pada waktu release 48 jam dan 72 jam. penyebab yang 
terjadi adalah kemungkinan pada konsentrasi tersebut menghasilkan kekuatan dinding mikrokapsul yang hampir sama. Peningkatan konsentrasi kitosan meyebabkan viskositas menjadi meningkat dan menghasilkan dinding mikrokapsul yang lebih padat dan kaku. Hasil yang sama juga dilaporkan oleh Nayak dkk (2009) dan Patel dan Patel (2014) yaitu peningkatan konsentrasi kitosan menyebabkan obat yang release menjadi rendah.

Pengaruh volume glutaraldehyde saturated toluene (GST) terhadap jumlah oleoresin jahe merah yang release dari mikrokapsul ditunjukkan pada Gambar 2.

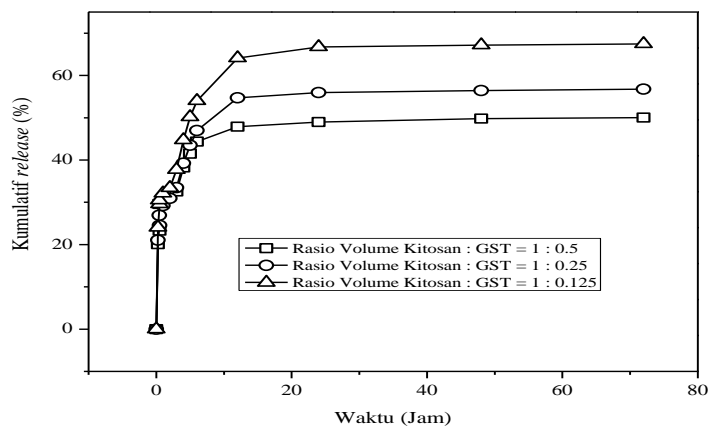

Gambar 2. Perubahan persen kumulatif release berdasarkan perubahan rasio volume kitosan dengan glutaraldehyde saturated toluene (GST) pada konsentrasi kitosan $4 \%$ (w/v)

Gambar 2 menunjukkan perubahan kumulatif release dari oleoresin jahe merah karena pengaruh volume glutaraldehyde saturated toluene (GST). Gambar 2 menujukkan bahwa semakin rendah volume GST menghasilkan kumulatif release yang semakin besar. kumulatif release tertinggi didapat dari volume GST yaitu $55,45 \%$, sedangkan kumulatif release terrrendah yaitu sebesar $50 \%$ diperoleh dari mikrokapsul yang dicrosslink dengan $20 \mathrm{~mL}$ GST.

Volume glutaraldehyde saturated toluene (GST) berpengaruh ikat silang antara gugus aldehida dengan gugus amino. Peningkatan volume GST menyebabkan ikat silang yang terbentuk menjadi lebih banyak sehingga dinding mikrokapsul lebih padat. Hal inilah yang menyebabkab oleoresin yang realese menjadi lebih kecil.

\subsection{Kinetika release}

Dari gambar 1 dan 2 kemudian digunakan untuk menghitung kinetika release menggunakan persamaan 1 sampai dengan 5. Dari persamaan tersebut dapat ditentukan konstanta-konstanta kinetika release menggunakan persamaan linierisasi. Tabel 1 menujukkan hasil perhitungan kinetika release berdasarkan perubahan konsentrasi kitosan sebagai bahan dinding mikrokapsul.

Model kinetika yang ditunjukkan oleh persamaan 1 sampai dengan 5 mempunyai karakter yang berbedabeda, misalkan kinetika release order nol menggambarkan sistem dimana laju release tidak dipengaruhi oleh konsentrasinya, order satu menggambarkan menggambarkan penyerapan dan/atau eliminasi beberapa obat walaupun sulit untuk mengkonseptualisasikan mekanisme ini berdasarkan teori, sedangkan model Korsmeyer-Peppas menggambarkan mekanisme release obat dari sistem polimer (Shruthi dkk, 2016; Dash dkk, 2010).

Tabel 1. Konstanta kinetika release mikrokapsul oleoresin jahe merah berdasarkan perubahan konsentrasi kitosan

\begin{tabular}{cccccccccccccc}
\hline \multirow{2}{*}{$\begin{array}{c}\text { Konsentrasi } \\
\text { kitosan (\%) }\end{array}$} & \multicolumn{2}{c}{ Order nol } & \multicolumn{2}{c}{ Order satu } & \multicolumn{2}{c}{ Higuchi } & \multicolumn{3}{c}{$\begin{array}{c}\text { Hixon- } \\
\text { Crowell }\end{array}$} & \multicolumn{3}{c}{ Korsmeyer-Peppas } \\
\cline { 2 - 14 } & $\mathrm{k}_{0}$ & $\mathrm{R}$ & $\mathrm{k}_{1}$ & $\mathrm{R}$ & $\mathrm{k}_{\mathrm{H}}$ & $\mathrm{R}$ & $\mathrm{k}_{\mathrm{H}-\mathrm{C}}$ & $\mathrm{R}$ & $\mathrm{k}_{\mathrm{K}-\mathrm{P}}$ & $\mathrm{n}$ & $\mathrm{R}$ \\
\hline 1 & 0.00009 & 0.4 & 0.000161 & 0.48 & 0.72 & 0.65 & 0.0002 & 0.46 & 3.945 & 0.41 & 0.74 \\
2 & 0.00009 & 0.45 & 0.000138 & 0.54 & 0.71 & 0.69 & 0.0002 & 0.51 & 3.881 & 0.39 & 0.74 \\
3 & 0.00008 & 0.44 & 0.000138 & 0.52 & 0.66 & 0.68 & 0.0002 & 0.49 & 3.828 & 0.39 & 0.73 \\
4 & 0.00008 & 0.42 & 0.000115 & 0.49 & 0.63 & 0.66 & 0.0002 & 0.46 & 3.837 & 0.39 & 0.73 \\
\hline
\end{tabular}

Tabel 2. Konstanta kinetika release mikrokapsul oleoresin jahe merah berdasarkan perubahan volume glutaraldehyde saturated toluene (GST)

\begin{tabular}{ccccccccccccc}
\hline $\begin{array}{c}\text { Volume } \\
\text { GST } \\
(\mathbf{m L})\end{array}$ & \multicolumn{2}{c}{ Order nol } & \multicolumn{2}{c}{ Order satu } & \multicolumn{2}{c}{ Higuchi } & \multicolumn{3}{c}{ Hixon-Crowell } & \multicolumn{3}{c}{ Korsmeyer-Peppas } \\
\cline { 2 - 12 } & $\mathrm{k}_{0}$ & $\mathrm{R}$ & $\mathrm{k}_{1}$ & $\mathrm{R}$ & $\mathrm{k}_{\mathrm{H}}$ & $\mathrm{R}$ & $\mathrm{k}_{\mathrm{H}-\mathrm{C}}$ & $\mathrm{R}$ & $\mathrm{k}_{\mathrm{K}-\mathrm{P}}$ & $\mathrm{n}$ & $\mathrm{R}$ \\
\hline 20 & 0.00007 & 0.36 & 0.00015 & 0.43 & 0.56 & 0.6 & 0.0001 & 0.41 & 4.121 & 0.38 & 0.7 \\
10 & 0.00008 & 0.42 & 0.00015 & 0.49 & 0.63 & 0.66 & 0.0002 & 0.46 & 3.837 & 0.39 & 0.73 \\
5 & 0.00008 & 0.37 & 0.00013 & 0.44 & 0.68 & 0.61 & 0.0002 & 0.41 & 3.999 & 0.4 & 0.85 \\
\hline
\end{tabular}


Dari tabel 1 dan 2 menunjukkan bahwa koefisien regresi terbaik yang dihasilkan dari model-model kinetika release dihasilkan dari model Korsmeyer-Peppas yaitu R2 = $0.7-$ 0,85 dengan nilai $\mathrm{n}$ yaitu mulai dari $0.38-0.41$. nilai $\mathrm{n}$ ini menunjukkan mekanisme release oleoresin jahe merah dari mikrokapsul. Mekanisme release yang dihasilkan dari model Korsmeyer-Peppas kemudian dibandingkan dengan Tabel 3 yang di buat oleh Ritger and Peppas, (1987).

Table 3. Eksponensial difusi (n) dan mekanisme release

\begin{tabular}{|c|c|c|c|}
\hline \multicolumn{3}{|c|}{ Eksponen difusi, n } & \multirow[b]{2}{*}{$\begin{array}{c}\text { Mekanisme } \\
\text { release }\end{array}$} \\
\hline Lapisan film & $\begin{array}{l}\text { Sampel } \\
\text { silinder }\end{array}$ & Bola & \\
\hline 0.5 & 0.45 & 0.43 & Difusi Fickian \\
\hline $0.5<\mathrm{n}<1$ & $\begin{array}{c}0.45<\mathrm{n}< \\
0.89\end{array}$ & $\begin{array}{c}0.43<\mathrm{n}< \\
0.85\end{array}$ & Non-Fickian \\
\hline 1.0 & 0.89 & 0.85 & $\begin{array}{l}\text { Case II } \\
\text { transport }\end{array}$ \\
\hline
\end{tabular}

Model Korsmeyer-Peppas dari penelitian ini dan mengacu pada Tabel 3 yaitu lebih kecil dari 0,43 untuk sampel bola, sehingga menunjukkan bahwa mekanisme release yang terjadi adalah secara difusi Fickian. Hal ini menunjukkan bahwa seluruh parameter yang dilakukan penelitian ini bahwa oleoresin jahe merah yang release secara difusi melalui dinding mikrokapsul. Nilai koefisien difusi yang dihitung dengan persamaan 6 dapat dilihat pada Tabel 4 .

Tabel 4. Nilai koefisien difusi

\begin{tabular}{cccc}
\hline $\begin{array}{c}\text { Konsentrasi } \\
\text { kitosan (\%) }\end{array}$ & $\begin{array}{c}\text { Koefisien } \\
\text { difusi } \\
\left(\mathbf{c m}^{2} / \text { detik }\right)\end{array}$ & $\begin{array}{c}\text { Volume } \\
\text { GST } \\
(\mathbf{m L})\end{array}$ & $\begin{array}{c}\text { Koefisien } \\
\text { difusi } \\
\left(\mathbf{c m}^{2} / \mathbf{d e t i k}\right)\end{array}$ \\
\hline 1 & $2,982 \times 10^{-13}$ & 20 & $3,058 \times 10^{-13}$ \\
2 & $2,807 \times 10^{-13}$ & 10 & $3,17 \times 10^{-13}$ \\
3 & $2,884 \times 10^{-13}$ & 5 & $3,675 \times 10^{-13}$ \\
4 & $3,17 \times 10^{-13}$ & & \\
\hline
\end{tabular}

Tabel 4 menunjukkan nilai koefisien difusi untuk release oleoresin jahe merah dari mikrokapsul yaitu mulai dari $2,807 \times 10-13 \mathrm{~cm} 2 /$ detik sampai dengan 3,675 x 10-13 $\mathrm{cm} 2 /$ detik. Nilai koefisien difusi pada mikrokapsul oleoresin jahe merah dari semua parameter adalah 10-13 sehingga nilai ini sudah sesuai dengan nilai koefisien difusi untuk solid yaitu diantara 10-14 sampai 10-10 m2/detik (Welty dkk, 2013).

\section{Kesimpulan}

Oleoresin jahe yang release dari mikrokapsul menghasilkan besaran yang berbeda disesuaikan dengan konsentrasi kitosan sebagai bahan dinding dan volume glutaraldehyed saturated toleuen (GST) sebagai crosslinker karena berpengaruh pada kekuatan dinding mikrokapsul yang dihasilkan. Semakin besar konsentrasi kitosan dan volume GST menghasilkan kumulatif release yang semakin kecil. Nilai koefisien regresi $\left(\mathrm{R}^{2}\right)$ tertinggi didapat dari model kinetika release Korsmeyer-Peppas yaitu $\mathrm{R}^{2}=0.73-0.85$ dengan nilai $\mathrm{n}=0.39-0.41$. Berdasarkan nilai $\mathrm{n}$ tersebut mekanisme release dari mikrokapsul oleoresin jahe merah adalah secara Fickian. Koefisien difusi yang dihasilkan yaitu $2.807 \times 10^{-13}$ - 3.675 x $10^{-13} \mathrm{~cm}^{2} /$ detik.

\section{Ucapan Terima kasih}

Penulis mengucapkan terima kasih kepada Kementerian Riset, Teknologi, Dan Pendidikan Tinggi Republik Indonesia (Kemenristek DIKTI) atas semua dana yang terlah diberikan melalui beasiswa BPPDN (Beasiswa Pendidikan Pascasarjana Dalam Negeri) dan juga kami mengucapkan terima kasih kepada Laboratorium Teknologi Polimer, Departemen Teknik Kimia, UGM atas semua fasilitas penelitian yang telah di sediakan.

\section{Daftar Pustaka}

\section{Jurnal (Journal)}

Bellik Y, 2014, Total antioxidant activity and antimicrobial potency of the essential oil and oleoresin of Zingiber officinale Roscoe. Asian Pacific Journal of Tropical Disease, Vol. 4 No. 1: 40- 44.

Campos E, Coimbra P, Gil MH, 2013, An improved method for preparing glutaraldehyde cross-linked chitosan-poly (vinyl alcohol) microparticles. Polymer Bulletin, Vol. 70 No. 2: 549-561

Dash, Suvakanta, Padala Narasimha Murthy, Lilakanta Nath, and Prasanta Chowdhury, 2010, Kinetic Modeling on Drug Release from Controlled Drug Delivery Systems. Acta Poloniae Pharmaceutica, Vol. 67 No. 3: 217-23

Dozie-Nwachukwu SO, Danyuo Y, Obayemi JD, Odusanya OS, Malatesta K, Soboyejo WO, 2017, Extraction and encapsulation of prodigiosin in chitosan microspheres for targeted drug delivery, Materials Science and Engineering C. Vol. 71: 268-278.

Freitas MN dan Marchetti JM, 2005, Nimesulide PLA microspheres as a potential sustained release system for the treatment of inflammatory diseases. International Journal of Pharmaceutics. Vol. 295, No. 1-2: 201-211

Islam S., Rahman Bhuiyan, MA., Islam, MN., 2017, Chitin and Chitosan: Structure, Properties and Applications in Biomedical Engineering. Journal of Polymers and the Environment, Vol. 25 No. 3: 854-866

Jameela SR, Jayakrishnan A., 1995, Glutaraldehyde crosslinked chitosan microspheres as a long acting biodegradable drug delivery vehicle: studies on the in vitro release of mitoxantrone and in vivo degradation of microspheres in rat muscle, Biomaterials. Vol. 16, No. 10: 769-775 
Jayanudin., Fahrurrozi M., Wirawan, SK., Rochmadi, 2018, Controlled Release Evaluation of Red Ginger Oleoresin Encapsulation using Simulated Gastric Fluid (SGF), Research Journal of Pharmacy and Technology. Vol. 11, No. 8: 3431-3436

Jayanudin., Fahrurrozi M., Wirawan, SK., Rochmadi. 2019. Mathematical modeling of the red ginger oleoresin release from chitosan-based microcapsules using emulsion crosslinking method. Engineering Science and Technology, an International Journal. Vol. 22, No. 2: 458-467

Manjanna KM, Shivakumar B, Kumar TMP, 2010, Microencapsulation: An Acclaimed Novel DrugDelivery System for NSAIDs in Arthritis. Critical Reviews $^{\mathrm{TM}}$ in Therapeutic Drug Carrier Systems, Vol. 27, No. 6: 509-545

Nayak UY., Gopal S., Mutalik S., Ranjith AK., Reddy MS., Gupta P., Udupa N., 2009, Glutaraldehyde crosslinked chitosan microspheres for controlled delivery of Zidovudine. Journal of Microencapsulation, Vol. 26, No. 3: 214-222.

Oboh G., Ayodele JA., Adedayo OA, 2012, Antioxidant and inhibitory effect of red ginger (Zingiber officinale var. Rubra) and white ginger (Zingiber officinale Roscoe) on $\mathrm{Fe} 2+$ induced lipid peroxidation in rat brain in vitro, Experimental and Toxicologic Pathology, Vol. 64, No.1-2: 31-36.

Ofokansi KC, Kenechukwu FC, Isah AB, Okigbo EL. 2013. Formulation and evaluation of glutaraldehydecrosslinked chitosan microparticles for the delivery of ibuprofen, Tropical Journal of Pharmaceutical Research, Vol.12, No.1: 19-25

Patel KS, Patel MB, 2014, Preparation and evaluation of chitosan microspheres containing nicorandil. International Journal of Pharmaceutical Investigation. Vol. 4, No.1: 32-37.

Ravindran P N., Nirmal Babu K., Shiva KN, 2004, Botany and Crop Improvement of Ginger. In: Ravindran PN.,
Nirmal Babu K. Ginger: The Genus Zingiber. CRC PRESS. Boca Raton, Florida, pp. 15-86

Ritger PL, Peppas NA., 1987, A simple equation for description of solute release II. Fickian and anomalous release from swellable devices. Journal of Controlled Release, Vol. 5, No. 1: 37-42.

Shaikh J, Bhosale R, Singhal, R. 2006, Microencapsulation of black pepper oleoresin. Food Chemistry, Vol.94, No. 1: $105-110$

Shoaib MH., Tazeen J., Merchant HA., Yousuf, RI. 2006, Evaluation of drug release kinetics from ibuprofen matrix tablets using HPMC. Pakistan Journal of Pharmaceutical Sciences, Vol. 19, No.2: 119-124

Shruthi SB, Roy P, Sailaja RRN, Sengupta C., 2016, Encapsulation and release characteristics of Marigold oleoresin in chitosan grafted sodium acrylate-coacrylamide. Advanced Materials Letters, Vol.7, No.10: 795-801

Siepmann J, Siepmann F., 2012, Modeling of diffusion controlled drug delivery. Journal of Control Release. Vol. 161, No.2: 351-362.

Thanoo, BC, Sunny MC, Jayakrishnan, A. 1992, Crosslinked Chitosan Microspheres: Preparation and Evaluation as a Matrix for the Controlled Release of Pharmaceuticals. Journal of Pharmacy and Pharmacology, Vol. 44, No.4: 283-286

Vaidya S, Bhosale R, Singhal RS., 2006, Microencapsulation of Cinnamon Oleoresin by Spray Drying Using Different Wall Materials. Drying Techology. Vol.24: 983-92.

Welty JR., Wicks CE., Wilson RE., Rorrer GL., 2007, Fundamentals of Momentum, Heat, and Mass Transfer. 5th edition. John Wiley \& Sons, Inc. pp. 398429. 